\title{
Políticas de Formação Inicial e Continuada de Docentes Alfabetizadores
}

\section{Policies for Initial and Continuous Education of Literacy Teachers}

\section{Políticas de formación inicial y continua de los profesores de alfabetización}

\section{Carmen Sá Brito Sigwalt'1 \\ Rosana de Albuquerque Sá Brito² \\ Sandra Regina Kirchner Guimarães ${ }^{3}$}

\section{Resumo}

Estudo que analisa três grandes momentos de formação docente de alfabetizadores e as políticas educacionais que os sustentam. O primeiro, denominado de tradicional; o segundo, chamado de construtivista; e o terceiro, que procura a superação dos dois primeiros momentos, buscando a junção das dimensões gráficas e semântica. O referencial de análise é a concepção de alfabetizar letrando, na qual a alfabetização (domínio do sistema gráfico) e o letramento (uso da leitura e da escrita nas diversas funções sociais) são trabalhadas conjuntamente. Os resultados do estudo evidenciaram os limites dos dois primeiros momentos e os avanços do terceiro período, bem como a necessidade da articulação de diferentes políticas junto às de formação docente.

Palavras-chave: Formação docente; Aquisição da linguagem escrita; Políticas educacionais.

\begin{abstract}
The present study analyses three major historic phases in the education of literacy teachers and their corresponding educational policies that provide support for each phase. The first phase refers to the so-called traditional method, the second one to constructivism, and the third refers to the whole language approach, which attempts to overcome the two previous perspectives by developing the graphic and the semantic dimensions together. The parameter for analysis is the assumption of literacy through the whole language approach in which learning to read and write (mastering the graphic system) and literacy (appropriate use of reading and writing in different social functions) are developed together. The results of the study point out the limits of the first two phases, the advances of the third phase, as well as the need to articulate the educational policies with other related policies.
\end{abstract}

Keywords: Teacher training; Acquisition of written language; Educational policies.

\section{Resumen}

1Doutora em Educação pela UFPR.Professora do Departamento de Planejamento e Administração Escolar do Setor de Educação da UFPR.

2Mestre em Letras pela UFPR e Doutora em Educação pela UFPR. Professora do Departamento de Letras Estrangeiras Modernas do Setor de Ciências Humanas, Letras e Artes da UFPR.

3 Doutora em Psicologia Escolar e do Desenvolvimento Humano pela USP. Professora do Departamento de Teoria e Fundamentos da Educação do Setor de Educação da UFPR. E-mail: srkguimaraes@uol.com.br 
El estudio analiza tres grandes momentos de las políticas de formación y educación del maestro de alfabetización. La primera, Ilamada tradicional; el segundo, denominado constructivista; y la tercera, que busca superar las dos primeras veces, la búsqueda de la unión de las dimensiones gráficos y semánticos. El marco analítico es alfabetizar letrando, en el que la alfabetización (dominio sistema gráfico) y el letramento (el uso de la lectura y la escritura en diversas funciones sociales) se trabajan juntos. Los resultados del estudio mostraron los límites de los dos primeros y los avances del tercer período, y la necesidad de coordinación de las diferentes políticas a la formación de los profesores.

Palabras clave: Formación del profesorado; Adquisición del lenguaje escrito; Políticas educativas.

\section{Introdução}

Na sociedade, cabe à educação o papel de preservação e transmissão das formas de vida humana, ou seja, da cultura. Esta é caracterizada pela forma escrita de registros culturais. Assim, a aprendizagem da leitura e da escrita assume preponderante significado. Embora esta aprendizagem seja fundamental para o acesso ao conhecimento sistematizado, observa-se que sua apropriação tem ocorrido de modo incipiente. Uma referência são os dados de rendimento escolar divulgados pelo Sistema Brasileiro de Ensino Básico (SAEB). Os alunos avaliados não apresentam um nível satisfatório no domínio da leitura e da escrita na sua língua materna, ou seja, são limitados na capacidade de leitura e interpretação de textos escritos. Os alunos terminam a quarta série do Ensino Fundamental com um nível crítico de desempenho nessa área de conhecimento, ficando muito distantes das habilidades que deveriam desenvolver ao final deste período de escolarização. Diante de tais resultados, uma questão se coloca: não estaria a escola brasileira atrelada a perspectivas metodológicas de ensino-aprendizagem da leitura e da escrita que têm dificultado a apropriação destes instrumentos básicos de inserção na sociedade letrada a todos os alunos? Quais os fundamentos que devem ser evidenciados na formação docente que possibilitem uma atuação efetiva no processo de aquisição e desenvolvimento da leitura e da escrita?

A História da Educação Brasileira, no que se refere ao processo de formação docente para sua atuação como alfabetizador, pode ser dividida em três grandes momentos: o primeiro, denominado momento tradicional; o segundo, chamado período construtivista; e o terceiro, uma tentativa de superação de propostas limitadas.

O presente estudo tem como objeto a análise destes três momentos da formação de alfabetizadores: o tradicional, o construtivista e a tentativa de superação destas duas abordagens. O referencial de análise é a concepção de alfabetizar-letrando, na qual a alfabetização (domínio do sistema gráfico) e o letramento (uso da leitura e da escrita nas diversas funções sociais) são trabalhados conjuntamente. Parte-se do princípio de que há necessidade da formação de os alfabetizadores considerarem a alfabetização e o letramento como ações indissociáveis.

Este trabalho tem como problema de investigação a seguinte questão: Como as propostas de formação de alfabetizadores consideram o pressuposto de alfabetizar-letrando?

Toma-se como hipótese que existe uma ênfase em uma dimensão em detrimento de outra nos referenciais políticos educacionais dos processos formativos. Alguns supervalorizam o domínio do sistema gráfico (alfabetização restrita), outros privilegiam a dimensão significativa, secundarizando o domínio sistemático da grafia.

Parte-se do princípio de que dominar a dimensão gráfica e significativa do processo de apropriação da linguagem escrita pressupõe não apenas saber grafar corretamente as palavras, mas saber usá-las em textos, respeitando suas dimensões semântica, sintática e pragmática. A dimensão semântica é a relação das palavras com os objetos, coisas ou pessoas; a sintática é a relação que as palavras mantêm entre si, e a pragmática é a relação das palavras com seus usuários. As três dimensões se complementam tanto na escrita como na oralidade. Os componentes sintáticos, semânticos e pragmáticos se encontram integrados de modo indissociável na realização concreta da língua (falada ou escrita). 
Portanto, saber ler não é apenas uma questão de deciframento de um código, mas envolve a possibilidade de compreensão textual. Saber escrever não se restringe a grafar palavras descontextualizadas, mas saber expressar ideias, o que exige, além de correção gramatical, a capacidade de estabelecer ligação de sentido que tornem o texto compreensível e que expressem um contexto em que a linguagem escrita esteja apoiada na interação verbal, revelando sua natureza social e viva.

Assim, o código é utilizado na interlocução, nas relações sociais que o constituem. A leitura e a escrita não podem ser vazias de conteúdo, significado e sentido. O seu ensino e a sua aprendizagem devem estar atrelados a situações reais de uso.

\section{Metodologia}

Esta investigação baseou-se na análise dos referenciais teórico-metodológicos que embasam a formação de alfabetizadores, procurando explicitar a concepção de linguagem escrita a que estão atrelados e, consequentemente, a concepção de ensino - aprendizagem da língua que veiculam. Levantou-se como pressuposto que as perspectivas tradicional e construtivista de formação docente não garantem a necessária articulação entre os eixos gráfico e semântico, ou seja, afastam-se da perspectiva de alfabetizar-letrando. O estudo foi desenvolvido por meio da análise de documentos que sustentam os três diferentes momentos de qualificação de alfabetizadores. Adotou-se como referencial de análise que o processo de ensino-aprendizagem inicial da escrita deve contemplar tanto o domínio do sistema gráfico quanto o uso da leitura e da escrita nas diferentes funções sociais.

\section{Análise e discussão}

O momento tradicional e o período construtivista foram analisados a partir da perspectiva de alfabetizarletrando, ponto de vista defendido neste artigo.

\section{Momento tradicional}

Antecedendo o momento tradicional, a leitura e a escrita eram práticas culturais cuja aprendizagem encontravase restrita a pouquíssimos e acontecia prioritariamente no ambiente doméstico, quando pais alfabetizados transmitiam estes conhecimentos a seus filhos ou, ainda, quando os privilegiados economicamente contratavam profissionais para realizar esta tarefa.

O processo era despossuído de fundamentos teóricos mais consistentes, se ensinava os rudimentos da leitura e da escrita baseando o trabalho, principalmente, num caminho no qual se apresentavam primeiramente as letras, depois a combinação destas em sílabas e, posteriormente, em palavras. As poucas escolas do Império (aulas régias) não fugiam da forma de ensino preconizadas no ambiente doméstico.

O primeiro período de formação docente, denominado de tradicional, tinha como princípio básico a ideia de formação inicial e pouquíssima preocupação com a formação continuada.

O trabalho de formação inicial para a futura atuação de alfabetizadores era organizado por meio dos cursos de preparação para o magistério, as chamadas escolas normais e regionais. Assim, ao dominar os diferentes métodos de alfabetização existentes, o futuro docente teria condições de adotar um dos métodos de ensino da língua ou poderia ser levado a construir seu próprio encaminhamento metodológico, que acabava resultando num método eclético. Ao assumir sua função docente nas redes públicas de ensino, aplicava em sala de aula o método de alfabetização determinado pela entidade mantenedora.

Segundo Mortatti (2008, p.467-476), da década de 1920 a 1970 ainda permanece a hegemonia dos métodos tradicionais de alfabetização com as suas diferentes propostas e toma corpo a postulação da necessidade do conhecimento do nível de maturidade para o aprendizado da leitura e da escrita - ênfase no teste ABC de 
Lourenço Filho, que veio articulado com os pressupostos da concepção pedagógica do Movimento da Escola Nova, que eram os conteúdos priorizados na formação dos futuros professores.

Segundo Kato (1999, p.5), nos congressos e seminários do início da década de 1980 ainda se percebia:

(...) uma preocupação obsessiva por parte dos professores por métodos de alfabetização, preocupação essa causada pela busca ansiosa de um instrumento seguro para a consecução dos objetivos mínimos da escola: ensinar a ler e a escrever.

A mesma autora também enfatiza que nos métodos tradicionais há excessiva preocupação com a escrita e pouca ênfase no desenvolvimento da leitura. Está subjacente a esta prática a ideia de que à produção segue-se automaticamente a recepção, ou seja, acredita-se que se o professor ensinar o aluno a escrever, ele aprenderá automaticamente a ler.

Bellenger (1979) afirma que os aspectos mecânicos e repetitivos dos métodos de alfabetização têm suas origens na Antiguidade e são marcados até a Idade Contemporânea. Embora tenham se apresentado com roupagens diferentes no decorrer da história da humanidade, sempre privilegiaram o domínio do sistema gráfico em detrimento do domínio da linguagem escrita em seu sentido mais amplo.

Pode-se afirmar que, de 1890 a meados de 1980, a prática pedagógica da alfabetização no Brasil estava centrada nas chamadas metodologias tradicionais que, embora mudassem na sua roupagem ou aparência, tinham todas a mesma essência, ou seja, partiam de uma concepção de linguagem escrita baseada apenas no domínio do sistema gráfico.

A concepção de linguagem que está presente na maioria dos métodos tradicionais de alfabetização vê a língua como um conjunto de formas prontas e acabadas que devem ser aprendidas. O encaminhamento destes métodos supervaloriza o sistema gráfico, secundarizando o trabalho da linguagem no seu sentido mais amplo, que é o trabalho com o significado, com o sentido.

Os métodos tradicionais estão atrelados a uma pedagogia centrada no professor e na transmissão do conhecimento. Conforme Becker (1993, p.12-58 e 107), esta concepção está apoiada na visão associacionista da psicologia, no behaviorismo e no neobehaviorismo de Watson e Skinner, e sua fundamentação epistemológica é dada pelo empirismo. Nessa perspectiva, parte-se do princípio de que o conhecimento se dá por força dos sentidos e a aprendizagem é vista como aquisição de algo externo ao sujeito. A mente acumula informações que, vindas de fora, são dadas por estímulos captados pelos sentidos. Assim, o conhecimento é entendido como acumulação ou soma de informações.

A aula expositiva é a expressão do empirismo. O professor acredita que basta expor bem (clareza lógica com imagens sensoriais, visuais e auditivas precisas) a matéria para garantir o aprendizado. A matéria, por meio do professor, deve penetrar nos sentidos (visão e audição) do aluno. Há uma concepção de conhecimento como produto acabado que deve ser apenas reproduzido. Está presente nessa concepção o enunciado de Thorndike (CABRAL e NICK, 2001, p.99) como lei do exercício, a partir da qual o sujeito da aprendizagem deve repetir o que foi exposto para que a matéria seja decalcada na mente.

A visão empirista muitas vezes está associada com as implicações apriorísticas (as condições de possibilidade do conhecimento são dadas na bagagem hereditária, ou seja, de forma inata ou maturacional). A visão de maturidade, por conseguinte, constitui o polo do desenvolvimento cognitivo. O professor que assume esta concepção acredita no poder de seu ensino para produzir aprendizagem e, se esta não ocorre, o problema ou a culpa é do aluno.

Em síntese, pode-se afirmar que as metodologias tradicionais estão baseadas em pressupostos inconsistentes do ponto de vista do alfabetizar-letrando, tais como: os textos como mero pretexto para apresentação de uma determinada letra ou sílaba; a submissão dos alunos a uma série de exercícios que os distanciam da real noção de texto; o trabalho com sílabas isoladas, palavras descontextualizadas; os treinamentos mecânicos de estruturas da língua elaboradas com critérios questionáveis de dificuldades; a concepção limitada de linguagem escrita; a ênfase absoluta no domínio do código gráfico; a ideia de que o preparo para a alfabetização estava centrada apenas no desenvolvimento motor e nas percepções; o treino repetitivo de padrões silábicos; a ênfase 
nas cópias e nos ditados, muitas vezes sem sentido; as afirmações equivocadas de que, na língua portuguesa, cada letra corresponde a um som. Estes, entre outros limites, foram aspectos priorizados nos cursos de formação de alfabetizadores e enfatizados durante décadas nas escolas de formação docente, desconsiderando a articulação entre a grafia das palavras e seu significado. Estes pressupostos impossibilitaram aos futuros docentes a compreensão da necessidade de ter em mente a indissociabilidade entre o domínio do sistema gráfico e sua dimensão significativa.

Os resultados da aplicação das metodologias tradicionais nos anos iniciais mostraram que mais de $50 \%$ dos alunos ficavam retidos já no primeiro ano da escola. A crença na não-aprendizagem era vista como problema do aluno que, provavelmente, passava fome e, por esta razão, pouco aprendia. Em decorrência desta visão, os governos passaram a investir em políticas de merenda escolar travestidas de programa educacional.

\section{Período Construtivista}

A partir da década de 1980 tem-se a hegemonia da perspectiva construtivista. Assim, nos cursos de formação para o magistério, a fundamentação teórica está bastante centrada na psicologia. Este período marca a formação dos alfabetizadores tendo por suporte, principalmente, os estudos da pesquisadora Emilia Ferreiro (1994, 1995, 1996) e pelas didáticas de alfabetização para cada nível de conceptualização da escrita elaboradas por Esther Pilar Grossi (1990).

Entre as políticas educacionais governamentais deste momento construtivista, destaca-se o PROFA (Programa de Formação de Professores Alfabetizadores), coordenado pelo MEC (Ministério de Educação), que foi idealizado no ano 2000 e lançado em 2001, com a proposta de nortear as ações educativas de alfabetização no Ensino Fundamental, Educação Infantil e Educação de Jovens e Adultos. O MEC coordenou este processo de formação continuada durante dois anos, mas o programa continuou através das iniciativas das Secretarias Municipais de Educação e Governos Estaduais. A ideia central do Programa era de suprir as necessidades teóricas e práticas dos docentes da rede pública e redefinir-Ihes um novo papel, referente às novas concepções do período sobre o processo de aprendizagem da língua escrita. O Programa é composto por três módulos, sendo que nos dois primeiros fica claramente explícita a concepção construtivista, evidenciada pela ênfase no processo de "construção" da escrita pelos alunos. No terceiro módulo, esta perspectiva não está mais presente; há uma alteração dos autores neste documento, e posições defendidas nos primeiros módulos desaparecem no terceiro caderno do programa. Encontra-se no primeiro módulo o registro de seu principal objetivo, que é demonstrar que a aprendizagem inicial da leitura e da escrita é resultado de um processo de construção conceitual que se dá pela reflexão do aprendiz sobre as características e funcionamento da escrita. Diversas afirmações retratam fielmente os pressupostos construtivistas, como: "(...) respeito aos diferentes ritmos e formas de aprendizagem; (...) acolhimento de diferentes hipóteses e falas dos alunos quando expressarem seus conhecimentos (...)" (p.10 e 11). Ou ainda:

(...) os alunos buscam soluções e as discutem com os parceiros... Não se trata de situações que permitem "aplicar" o que já se sabe, mas sim daquelas que possibilitam produzir novos conhecimentos a partir dos que já se tem, e em interação com novos desafios. (p.13)

A figura do professor não é ressaltada e há uma ênfase na ideia de que os alunos devem produzir conhecimentos. Sobre este assunto, Klein (2001, p.4-8) destaca:

(...) nas concepções atuais, firmam-se posições que acentuam o papel do aluno, afirmando-o como sujeito do processo, na medida em que Ihe outorgam a função de construir seu próprio "conhecimento". (...) Partindo-se do pressuposto de que o conhecimento é uma produção social e, portanto, envolve uma ampla teia de sujeitos e relações e resulta de uma complexa base de conhecimentos já elaborados, parece evidente a dificuldade de 0 aluno, individualmente, como fruto de sua própria subjetividade, "produzir seu próprio conhecimento" (...). A prática pedagógica constitui uma relação entre dois sujeitos, com características específicas. Os sujeitos são, é óbvio, o professor e o aluno, e a relação que se estabelece entre eles é de ensino-aprendizagem... a função do ensino fundamental: é um nível de escolarização que objetiva proporcionar o domínio básico dos conhecimentos científicos já produzidos na sociedade[...]. 
A ideia de que qualquer conhecimento é "construído" está presente não apenas na concepção de como se dá o processo de aquisição da leitura e da escrita, mas também em qualquer relação de aprendizado, obscurecendo o papel da transmissão de conhecimentos.

Há um item no Programa denominado de Didática da Alfabetização: necessidade de deslocar o olhar de "como se ensina" para "como se aprende". Este título é bastante significativo, pois demonstra que esta abordagem privilegia a discussão sobre como o aluno aprende, secundarizando como se ensina. Destacar um dos elementos em detrimento do outro é no mínimo equivocado. Há uma abordagem marcante no Programa para que o professor conheça os diferentes níveis de conceptualização da escrita propostos por Emilia Ferreiro, atendendo esses estágios com atividades diferenciadas a partir das quais cada aluno desempenhe suas tarefas de acordo com o seu conhecimento sobre a escrita. É importante ressaltar que não aparece nenhuma sugestão de como fazer o aluno passar de um nível mais elementar para um nível mais avançado. Outro aspecto do Programa presente nos dois primeiros módulos é o fato de apresentarem algumas sugestões de atividades com textos, mas não destacam os pressupostos teóricos necessários que levem os professores a entender porque devem trabalhar com textos e não apenas com palavras soltas, sílabas ou letras desvinculadas de um contexto significativo. Segundo a concepção dos primeiros módulos do Programa, o válido é a busca do aluno, a chamada reflexão sobre a escrita, não devendo o professor mostrar como se dá a escrita convencional, e sim, esperar que o aluno a descubra.

O módulo 3 do Programa apresenta uma diferença significativa da concepção teórica sobre o processo de alfabetização. Ao contrário dos dois primeiros módulos, o terceiro apresenta uma abordagem que enfatiza a necessidade de um professor que, de fato, ensine. Esta constatação está presente nas nove diferentes unidades que compõem o terceiro módulo. A seguinte citação é exemplar (p.127):

(...) não é possível que os alunos aprendam sozinhos. É preciso garantir que, enquanto sua capacidade de produzir textos avança, os alunos vivenciam também a oportunidade de pensar e aprender sobre a escrita correta da palavra. (...) o professor deve considerar que 0 aluno precisa de ajuda para se apropriar da forma padrão (...).

As diversas abordagens trabalhadas nos cursos de formação de professores a partir da década de 1980 tiveram um mesmo pressuposto teórico, ou seja, a premissa de que o sujeito que adquire a língua escrita passa por um processo ativo de construção de hipóteses sobre a estrutura da língua em que deixa de ser um mero receptor de um ensino baseado fundamentalmente na figura de um professor que ensina para uma nova concepção, na qual o suporte básico está sustentado na perspectiva de que existe um aluno que aprende e que esta aprendizagem se dá através de um processo construtivo.

É importante ressaltar que vivia-se um momento em que uma parcela significativa da população escolarizada não conseguia sucesso no processo de alfabetização tradicional e a busca de soluções "milagrosas" era bastante tentadora. É neste contexto que nos cursos de formação docente, quer inicial ou continuada, os estudos de Emilia Ferreiro ganham destaque e diferentes interpretações de sua teoria resultaram em propostas metodológicas algumas vezes equivocadas.

Embora sua teoria não pretendesse ser um guia para o professor, mas oferecer elementos de reflexão e fundamentação teórica para o processo evolutivo de descoberta da escrita pela criança, seus estudos marcaram acentuadamente a formação dos professores alfabetizadores e, consequentemente, as práticas pedagógicas das turmas de alfabetização.

A psicogênese da língua escrita, tal como a descrevem Ferreiro e Teberosky (1985), está assente em uma teoria construtivista de aprendizagem: uma teoria que vê o aprendiz como sujeito de sua própria aprendizagem. Um aprendiz que não é alfabetizado pelo professor, mas que alfabetiza a si mesmo em interação com o objeto desse conhecimento: a escrita. Uma teoria que supõe que a criança é capaz de aprender a ler e a escrever através de um processo ativo de descobertas e de construção de hipóteses, que tanto melhor se realiza quanto menor for a interferência do professor. 
Os estudos de Ferreiro, no que se refere à alfabetização, não resultaram numa melhora substantiva do processo ensino-aprendizagem desenvolvido nas escolas. Novos equívocos foram somados aos velhos equívocos, o que impediu que houvesse um salto qualitativo no trabalho escolar com a língua escrita nas séries iniciais do Ensino Fundamental. Em decorrência disso, era possível encontrar, no período, nos cursos de formação para o Magistério enquanto orientações e nas classes de alfabetização enquanto ações travestidas de novas teorias, os antigos procedimentos tradicionais: treinamento e habilidades perceptuais e motoras; fragmentação do ensino da língua com o uso de diferentes cartilhas com seus pseudotextos, suas etapas, suas graduações de dificuldades.

O momento construtivista foi caracterizado por uma clara dissociação entre o ensinar e o aprender. Possivelmente para marcar uma oposição ao chamado ensino tradicional centrado nos conteúdos a serem trabalhados, passa-se a secundarizar os conteúdos e o processo de ensino e a supervalorizar apenas o aprendizado. Esta perspectiva parece estar inadequada, pois as duas dimensões (ensinar e aprender) devem estar articuladas com o objeto de conhecimento em pauta. No caso da alfabetização, a escrita da língua portuguesa e, portanto, o seu conteúdo não pode ser desconsiderado.

O Construtivismo tem suas bases no cognitivismo. O foco está em como o aluno (alfabetizando) aprende. Este aluno é visto como sujeito da aprendizagem e só aprende a língua escrita elaborando hipóteses e estratégias sobre ela. O professor é visto como um facilitador, problematizador, que organiza atividades que favorecem a reflexão sobre a escrita. Apoia-se na capacidade do sujeito refletir, interferir, estabelecer relações, processar e compreender informações, transformando-as. A concepção de aprendizagem é baseada na compreensão, no estabelecimento de relações. A alfabetização é vista como processo de construção conceitual, contínuo, iniciado muito antes de o aluno ir para a escola e que se desenvolve, simultaneamente, dentro e fora da sala de aula. Alfabetizar significa construir conhecimento. A língua é concebida como sistema de representação, como um objeto de conhecimento construído socialmente. O aprendizado do sistema de escrita é concebido como resultado de processo ativo no qual o sujeito da aprendizagem, desde os seus primeiros contatos com a escrita, constrói e reconstrói hipóteses sobre a natureza e o funcionamento da língua escrita. O texto é indicado como núcleo do trabalho com a língua e os erros cometidos pelos alunos durante o processo são vistos como tentativas de acerto, sendo importantes para a construção da escrita pela criança.

As propostas de formação docente apoiadas na psicogênese da escrita demonstram limites na articulação das dimensões do alfabetizar e letrar. Ao enfatizarem a construção do conhecimento pelo aluno, aguardam que o domínio do sistema gráfico, o alfabetizar, aconteça em decorrência do contato do aluno com textos. Assim percebese nas propostas construtivistas um distanciamento do pressuposto de alfabetizar-letrando. Ao supervalorizar a dimensão significativa, caem num equívoco de acreditar numa aprendizagem espontânea da escrita alfabética.

\section{Alfabetizar-letrando}

O terceiro momento de formação docente é concretizado pela suspensão da visão tradicional e construtivista e tem influência da concepção de letramento, que é incorporada como contribuição significativa na superação dos níveis restritos das duas perspectivas anteriores. Assim, este período de formação de alfabetizadores se dá a partir do final da década de 1990 e início dos anos 2000, com contribuições significativas de diferentes autores. Entre outros, destacam-se: Morais (2006), Klein (1990, 2000, 2006), Soares (1998, 2010), Faraco (2012) e Albuquerque, Morais e Ferreira (2008), que se debruçam sobre a problemática do ensino-aprendizagem da língua materna e socializam suas produções através de diferentes obras que não se restringem a apenas uma das dimensões do processo, ou seja, tratar apenas do ensino tal como propuseram os autores tradicionais ou abordar somente como se dá o processo de aprendizagem dos alunos conforme a concepção construtivista.

O novo paradigma de qualificação docente salienta a necessidade de uma sólida formação inicial, ao mesmo tempo em que destaca a importância do processo de capacitação continuada e passa a conceber a 
alfabetização e o letramento, que embora tenham conceitos distintos, como ações indissociáveis - em outras palavras, o docente deve ser qualificado de maneira a ser capaz de alfabetizar-letrando, ou seja, ensinar a ler e escrever no contexto das práticas sociais da leitura e da escrita, de modo que os alunos se tornem, ao mesmo tempo, alfabetizados (dominando o sistema gráfico da língua portuguesa) e letrados (sendo capazes de fazer uso efetivo da leitura e da escrita).

Superando a estreiteza dos dois primeiros momentos de formação, há que se adotar, nos cursos de formação inicial e continuada, uma concepção de língua escrita enquanto um sistema de representação, em que a grafia das palavras e seus significados estão associados, encaminhando o processo de alfabetização e letramento para além do mero domínio do sistema gráfico, propondo o efetivo domínio da linguagem escrita tomada na sua totalidade.

Pode-se afirmar que, nos documentos oficiais das políticas educacionais do governo federal, embora o PROFA (Programa de Formação de Alfabetizadores) tenha uma perspectiva Construtivista nos dois primeiros módulos, a partir da Unidade 5 do terceiro Módulo já está presente a perspectiva de alfabetizar-letrando. Neste terceiro momento de formação docente, o MEC lança o Programa Pró-Letramento (2007). É um programa de formação continuada de professores visando à melhoria da qualidade da aprendizagem da leitura e da escrita e Matemática nos anos iniciais do Ensino Fundamental. O Pró-Letramento se estrutura de forma integrada, envolvendo o MEC, Universidades e Sistemas de Ensino. A concepção de alfabetizar-letrando está presente em todos os fascículos do Programa e representa um salto qualitativo nas políticas educacionais de formação de alfabetizadores. Há uma unidade nas concepções de ensino, de aprendizagem, de alfabetização e de letramento, embora a produção do material tenha envolvido a participação de autores distintos, oriundos de diferentes Universidades (Universidade Federal de Minas Gerais, Universidade Federal de Pernambuco, Universidade Estadual de Campinas, Universidade Estadual de Ponta Grossa e Universidade de Brasília). A necessária indissociabilidade entre o domínio do sistema gráfico e a dimensão significativa está presente nos diferentes fascículos do Programa. O Pró-Letramento contempla o que se exige de um programa de formação docente e, além de fundamentos claros que explicitam as concepções de alfabetização, letramento, ensino e aprendizagem adotadas, realiza orientações coerentes com os fundamentos sobre como desenvolver o processo de aquisição e desenvolvimento da leitura e da escrita. Está presente no Programa a articulação entre teoria e prática numa concepção interacionista de linguagem, além de definir subsídios para o fazer pedagógico, apresentando sugestões de atividades que garantam a necessária articulação entre a dimensão gráfica e significativa da língua escrita.

Destaca-se que o limite do Pró-Letramento é o de não ter enfatizado a necessidade de outras políticas junto às de formação docente, como: melhoria das condições de trabalho, de salário, de jornada dos professores, de verbas suficientes para a implantação e desenvolvimento de programas de formação continuada.

Entre as publicações sobre a apropriação da linguagem escrita, que representa um importante referencial das políticas educacionais do Ministério da Educação e que tem por base a perspectiva do alfabetizar-letrando, destaca-se o documento: A criança de seis anos, a linguagem escrita e o Ensino Fundamental de nove anos de autoria de Maciel, Baptista e Mourão (2009).

\section{Considerações Finais}

O estudo demonstrou que as propostas de formação docente sustentadas pelas concepções tradicional e construtivista se afastam da perspectiva de alfabetizar-letrando.

A visão tradicional foca sua ação apenas no domínio do sistema gráfico. As considerações teóricas sobre a escrita da língua portuguesa, suas características, regularidades e irregularidades, a dimensão gráfica e fonética da língua são saberes desconsiderados. Havia uma separação clara entre conteúdo a ser trabalhado e a forma de encaminhamento desse conteúdo. O importante era o professor dominar a maneira de ensinar, 
desconsiderando que conteúdo estava sendo ensinado. No caso da alfabetização, um conhecimento mais sustentado sobre a língua portuguesa.

No período marcado pelo construtivismo, supervalorizou-se a dimensão significativa, e os documentos oficiais deste momento sugerem aos professores que a aprendizagem da escrita alfabética possa ocorrer de forma espontânea. O conhecimento da Psicogênese da Língua Escrita passa a ser o eixo fundamental que sustenta as políticas de formação docente.

A formação embasada na visão do alfabetizar-letrando concebe a alfabetização e o letramento como ações indissociáveis e trata do processo de ensino e de aprendizagem como processos distintos, mas articulados, formando uma unidade.

Há necessidade de, na efetivação de políticas de formação inicial e continuada de professores, a compreensão do que é ensinar, do que é aprender e do objeto do conhecimento e, no caso do ler e do escrever, ter-se profundo domínio teórico sobre a Língua Portuguesa e saber didatizar este conhecimento. No entanto, não se forma o professor alfabetizador apenas com disciplinas específicas, mas com a articulação de todas as ciências contemporâneas que constituem os currículos dos cursos de magistério. Este processo precisa vir acompanhado das demais políticas que garantam as condições satisfatórias do trabalho docente. Em síntese, a possibilidade da organização do trabalho pedagógico compatível com as necessidades e os recursos contemporâneos.

Procurou-se neste estudo destacar uma das dimensões políticas da formação de alfabetizadores, ou seja, a concepção de ensino-aprendizagem de língua que sustentou cada um dos momentos de formação docente de alfabetizadores. Concorda-se com Mortatti (2010, p.331) quando afirma: (..) a necessidade de pensar nas políticas públicas para o ensino e a aprendizagem iniciais da leitura e escrita com base no pressuposto óbvio de que decisões de ordem teórico-epistemológica ou técnica são também políticas.

\section{Referências}

ALBUQUERQUE, E. B. C.; MORAES, A. G. e FERREIRA, T. B. E. As práticas cotidianas de alfabetização: o que fazem as professoras? In: Revista Brasileira de Educação. Rio de Janeiro, RJ, v. 13. n. 38 maio/agosto, 2008.

BELLENGER, L. Os métodos de leitura. Rio de Janeiro, RJ: Zahar Editores, 1979.

BECKER, F. A epistemologia do professor:o cotidiano da escola. Petrópolis, Rio de Janeiro, RJ: Vozes, 1993.

BRASIL, Ministério da Educação. Resultados do SAEB. Brasília: INEP, 2007. Disponível em: http://www.inep. gov.br/download/saeb/2005/saeb1995.2005.pdf. Acesso em 08/09/2011.

BRASIL. Ministério da Educação. Secretaria de Educação Fundamental. PROFA - Programa de Formação de Professores Alfabetizadores. Brasília: MEC/SEF, 2001.

CABRAL, A.; NICK, E. Dicionário técnico de psicologia. São Paulo, SP: Cultris, 2001.

FARACO, C. A. Linguagem Escrita e Alfabetização. São Paulo, SP: Contexto, 2012, $1^{a}$ edição.

FERREIRO, E.; TEBEROSKY, A. A Psicogênese da língua escrita. Porto Alegre, RS: ArtMed, 1985.

GROSSI, E. P. Didáticas. v.1,2 e 3. Porto Alegre, RS: Paz e Terra, 1990.

KATO, M. O aprendizado da leitura. 5ª edição. São Paulo, SP: Martins Fontes, 1999.

KLEIN, L. R. Quem tem medo de ensinar?. $4^{\circ}$ Edição. São Paulo: Cortez, 2006.

Proposta Metodológica de Língua Portuguesa para o Ensino Fundamental. In: Cadernos da

Escola Guaicurú. v. 5. Mato Grosso do Sul, MS: SEED, 2000.

Considerações sobre o direito à educação. Curitiba, PR: NUPE/Marx/UFPR, 2006.

Fundamentos para uma proposta pedagógica. 2001. Disponível emhttp://www.gestaoescolar. 
diaadia.pr.gov.br/arquivos/File/otp/docs_pdf/fundamentos_prop_ped.pdfAcesso em 08/10/2012. ; SHAFASCHEK, R. Uma proposta de alfabetização, Curitiba, PR: SEED/PR, 1990.

MACIEL, F. I. P.; BAPTISTA, M. C.; MONTEIRO, S. (orgs). A criança de seis anos, a linguagem escrita e o Ensino Fundamental de Nove Anos. MEC/SEB, Diretoria de Concepções e Orientações Curriculares para a Educação Básica. Coordenação Geral de ensino Fundamental. Belo Horizonte, MG: UFMG;FaE/CEALE, 2009.

MORAIS, A. G. Concepções Metodológicas de Alfabetização: por que é preciso ir além da discussão sobre velhos 'métodos'?. - $1^{a}$ versão, 2006 - 2012. Disponível em: http://flautas.wordpress.com/2010/10/03/ metodos-de-alfabetizacao/Acesso em 12 de janeiro de 2012.

MORTATTI, M.R.L. Alfabetização no Brasil: cojecturas sobre as relações entre políticas públicas e seus sujeitos privados. In Revista Brasileira de Educação, v.15 n.44 maio/ago. 2010.

A "querela dos métodos" de alfabetização no Brasil: contribuições para metodizar o

debate. In: Revista Acoalfaplp: Acolhendo a alfabetização nos países de língua portuguesa. ano 3, n. 5, São Paulo, SP, 2008. Disponível em < HTTP:// WWW. Acoalfaplp.net >. Acesso em 03 setembro de 2011.

SOARES, M. Letramento: Um tema em três gêneros. Belo Horizonte, MG: Autêntica, 1998. Alfabetização e Letramento. In: Orientações Pedagógicas para os Anos Iniciais do Ensino Fundamental de Nove Anos. Curitiba, PR: SEED, 2010.

Recebido em Dezembro de 2013 | Aprovado em Fevereiro de 2014 